\title{
The kinesthetic spatial aftereffect as a function of the angular displacement of the joints of the arm
}

\author{
G. SINGER, F, V. FLANAGAN, AND J, K, COLLINS \\ UNIVERSITY OF SYDNEY
}

The magnitude of the kinesthetic spatial aftereffect following different angular displacements from the vertical and horizontal planes during stimulation was examined in two experiments using $278 \mathrm{Ss}$. Both Gibson's direct and indirect effect were found when angular displacements were away from the vertical, however, a bimodal pattem was observed in both experiments when stimulation was away from the horizontal. An explanation for the interaxial difference cannot be provided by conventional theories and must be sought in a consideration of the structure of the joints which are involved with the production of the aftereffect.

Modifications of spatial judgments which occur following stimulation of those sensory systems capable of spatial discrimination have been referred to as negative (Gibson, 1933), figural (Köhler \& Wallach, 1944), and spatial (Day \& Singer, 1964) aftereffects.

Gibson and Radner (1937) regarded the sensory axes of space as orthogonal and consequently interdependent just as the vertical and horizontal planes are orthogonal. They demonstrated that the orthogonal relationship between the vertical and horizontal tended to be invariant when spatial judgments were changed following stimulation with a tilted object. Gibson's theory of adaptation towards a norm depended on the finding that as the tilt of an inspection-figure (IF) increased from zero through to $45^{\circ}$, the aftereffect would first increase to a maximum then decrease to zero at $45^{\circ}$, as no normalization to either axis would occur. With tilts greater than $45^{\circ}$ an indirect effect occurred with settings in the opposite direction to the angle of tilt.

Köhler (1965) proposed an explanation of the aftereffect in terms of repulsion. He stated that "the continual presence of a figure in a given place operates against the further presence of the figure" (p. 63). This theory predicts that an aftereffect will be observed when the test figure (TF) and the IF are spatially proximal. Consequently, if an aftereffect is to be observed within certain spatial limits of proximity of the IF and TF, then once the effect has disappeared (i.e., the spatial limit has been reached) no further aftereffect can be explained in terms of satiation and repulsion.

It is of interest for the general theory of these aftereffects to establish the functional relationships between these effects and intensity, spatial, and temporal variables. The aim of the experiments reported here was to establish the function of the spatial determinants of a kinesthetic aftereffect involving the major axes of space.

\section{EXPERIMENT 1}

The first experiment was designed to test the effects of angular movement of the right shoulder joint on judgments of the vertical and horizontal planes.

\section{Method}

Apparat $u$ s. The apparatus which is shown in Fig. 1 (Collins, 1967a) was designed to move the extended
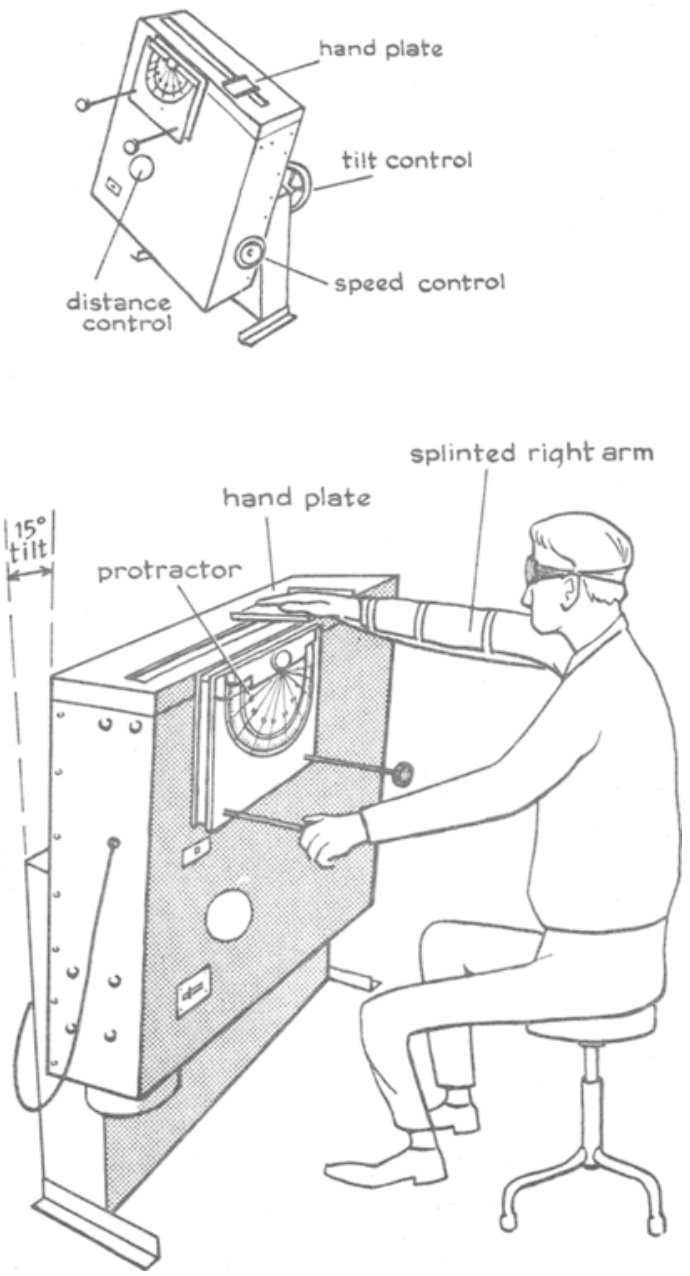

Fig. 1. Apparatus used in Experiment 1 showing the method of stimulation with an inset at the top showing the various controls. 
arm and hand laterally across a slanted surface. The movement was achieved by a motor-driven carriage to which the hand was fixed during the stimulation period. The stimulation angle could be adjusted through $90^{\circ}$, but the hand tray, which was independently adjustable, was always horizontal for Ss making settings to the horizontal, and vertical for Ss making vertical settings. The carriage moved from side to side through a distance of $18 \mathrm{in}$. at a constant rate of 40 times per minute. Before and after this period of stimulation $S$ adjusted a $14 \times 3$ in. bar to apparent horizontality or verticality depending on the condition.

Subjects, One hundred and sixty-eight male and female students acted as Ss. They were all drawn from an introductory course in psychology and none of them had previously undertaken a task of this nature. They were all right hand dominant with no known injury to the right shoulder joint.

Procedure. The Ss were alternately allocated to one of 14 experimental conditions on reporting to the laboratory. The apparatus was horizontal and the hand tray was covered when they entered so that no stimulus cues would be available. Each $S$ was given five practice trials at setting the test bar to the horizontal or vertical plane to familiarize him with the setting procedure. A trial consisted of five pretests, a $3 \mathrm{~min}$ stimulation period during which the extended arm was moved by the apparatus, and one posttest. During the pretest and posttest $S$ was required to set the bar within a 10 sec period by moving the straightened arm back and forth with the fingers extended along the edge.

During stimulation the apparatus was tilted down on the right. The left hand was used for manipulation of the controls. The $\mathrm{S}$ was not told that the apparatus would be tilted. The 14 experimental groups were comprised of seven groups who made judgment of the horizontal and seven groups who made judgment of the vertical following angular stimulation of $0^{\circ}, 15^{\circ}, 30^{\circ}$, $45^{\circ}, 60^{\circ}, 75^{\circ}$, and $90^{\circ}$ away from one of these axes. An adjustable stool was used so that $S$ 's shoulder height could be adjusted to the height of the test bar. Each $S$ was tested only once to eliminate the possible introduction of a learned effect (Collins \& Singer, 1967), a single posttest only was given and the time taken between cessation of stimulation and the completion of the posttest was recorded (Singer \& Day, 1965).

\section{Results}

The differences between the mean of the pretests and the posttest is the measure of the aftereffect. The means of the aftereffects together with the standard deviations and adjustment times are shown in Table 1. Adjustment times for four of the conditions were not available owing to a procedural error although there was no reason to suspect that these would be any different from the recorded adjustment times.
Table 1. Mean aftereffects and SDs (in degrees) together with adjustment times for each condition of Experiment 1

\begin{tabular}{lcccccccc} 
& \multicolumn{8}{c}{ Displacement from horizontal axis } \\
& $0^{\circ}$ & $15^{\circ}$ & $30^{\circ}$ & $45^{\circ}$ & $60^{\circ}$ & $75^{\circ}$ & $90^{\circ}$ \\
\hline Mean & -0.15 & 2.36 & 2.44 & 0.75 & 2.82 & 2.04 & -0.32 \\
SD & 2.43 & 2.11 & 2.44 & 1.93 & 1.99 & 1.97 & 2.81 \\
Adiustment time & 8.1 & 7.7 & - & - & 7.1 & 7.1 & 7.0 \\
Significance & $\mathrm{NS}$ & $*$ & $*$ & $\mathrm{NS}$ & $*$ & $*$ & $\mathrm{NS}$ \\
& \multicolumn{6}{c}{ Displacement } & from vertical axis \\
& $0^{\circ}$ & $15^{\circ}$ & $30^{\circ}$ & $45^{\circ}$ & $60^{\circ}$ & $75^{\circ}$ & $90^{\circ}$ \\
\hline Mean & 0.32 & 2.02 & 2.93 & 0.40 & -2.64 & -0.50 & 0.15 \\
SD & 3.76 & 3.05 & 3.92 & 1.89 & 3.22 & 2.25 & 2.37 \\
Adjustment time & 7.2 & 6.7 & 7.1 & - & 6.5 & 7.1 & - \\
Significance & $\mathrm{NS}$ & $*$ & $*$ & $\mathrm{NS}$ & $*$ & $\mathrm{NS}$ & $\mathrm{NS}$ \\
\hline
\end{tabular}

* Significant at 0.05 level

The mean square within groups estimation of the population variance was used to compute the confidence interval for a significant deviation from zero $(\alpha=0.05)$ with $k(n-1)$ degrees of freedom (Rodger, 1965). The difference needed for a significant deviation from zero had to exceed $\left|1.35^{\circ}\right|$ for the horizontal axis (MSW = 5.61, df =77), and $\left|1.81^{\circ}\right|$ for the vertical axis (MSW = $9.88, \mathrm{df}=77$ ). The significance of the results are shown in Table 1. The most noticeable feature is the interaxial difference between judgments of the horizontal and the vertical at the various angles.

\section{EXPERIMENT 2}

The inter-axial difference between the aftereffect produced by angular displacement from the vertical and that produced by displacement from the horizontal, was completely unexpected. The vertical observations can be both predicted from and explained by Gibson's theory, particularly the disappearance of an aftereffect at $45^{\circ}$ and the reappearance of the opposite effect with stimulus angles beyond this point. However, the reappearance of a positive effect is inexplicable in terms of either Gibson's adaptation theory or Köhler's satiation theory. The aim of the second experiment was to see if the findings for the horizontal stimulation condition could be cross validated with a different kinesthetic aftereffect task.

\section{Method}

Apparatus. The apparatus shown in Fig. 2 (Collins, 1967b), was designed to allow different angular displacement of the shoulder joint without movement. It consisted of a hand-grip attached to a metal shaft which protruded through a wooden screen. To the rear of the shaft was attached a sharpened metal pointer which enabled readings to be taken on a $360^{\circ}$ protractor scale to the nearest $0.5^{\circ}$. The hand-grip could be moved by $S$ to make judgments of horizontality or verticality before and after a period of stimulation during which it could be fixed by $E$ in any position with a screw clamp. 


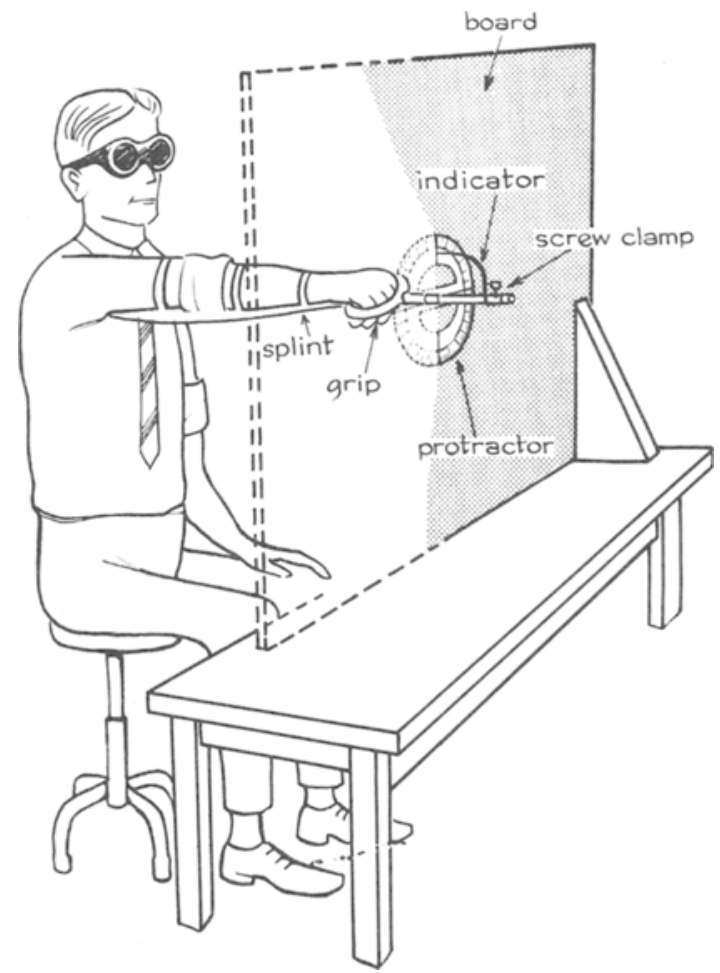

Fig. 2. Apparatus used in Experiment 2 to produce the kinesthetic displacement aftereffect in which Ss were required to set a hand-grip in the horizontal plane by pronation of the forearm.

Subjects. One hundred and ten male and female university students acted as Ss. They were all drawn from an introductory course in psychology and none of them had previously undertaken a task of this nature.

Procedure. The Ss were alternately assigned to one of 11 different experimental groups on reporting to the laboratory. They were blindfolded by opaque goggles and were fitted with a special splint, which kept the arm straight but which did not restrict the pronation or supination of the forearm. Five practice trials setting the hand-grip in the horizontal plane by pronation of the forearm, were given to familiarize $S$ with the apparatus. All Ss were instructed to take hold of the hand-grip rather than to place their finger-tips on it. They were told to make a setting to the horizontal as quickly as possible but not to sacrifice accuracy for speed. A trial consisted of four pretest judgments, $90 \mathrm{sec}$ stimulation period during which $\mathrm{S}$ held the hand-grip at the displacement angle, and one posttest. The stimulus angles, in degrees displacement from the horizontal, were $0^{\circ}, 10^{\circ}, 20^{\circ}, 30^{\circ}, 40^{\circ}, 45^{\circ}$, $50^{\circ}, 60^{\circ}, 70^{\circ}, 80^{\circ}$, and $90^{\circ}$. Half the Ss were given stimulation with the grip tilted up on the right and the other half with it up on the left. Half the Ss used their preferred arm while the other half used their nonpreferred arm.

\section{Results}

The mean difference between the pretests and posttest, together with the standard deviations and adjustment times are shown in Table 2. The significance of each of the differences from zero was tested using the mean square within groups estimation of the population variance as in an analysis of variance with $k(n-1)$ degrees of freedom (Rodger, 1965). The difference needed for a significant deviation from zero $(\alpha=0.05)$ had to exceed $\left|2.46^{\circ}\right|$ using the $t$ test with 99 degrees of freedom (MSW $=15.39$ ). The significance of the results are shown in Table 2.

\section{Discussion}

The results of the second experiment generally supported the earlier finding (see Fig. 3), with the exception that a significant aftereffect was found after stimulation at $45^{\circ}$. However the bimodal pattern, particularly the decrease in the size of the aftereffect at $45^{\circ}$ when stimulation was away from the horizontal, was quite marked. The aftereffect at $45^{\circ}$ is different from zero, but is also different from the aftereffects at $30^{\circ}, 40^{\circ}, 50^{\circ}, 60^{\circ}$, and $70^{\circ}$.

The results indicate that the traditional "one process" theories of Gibson and Köhler are inadequate explanations of the aftereffects induced by prolonged kinesthetic stimulation. Gibson's theory of adaptation to the spatial norm can account for some of the findings of the first experiment. The settings to the vertical norm support his predictions. There is a positive aftereffect for angles close to the spatial norm which disappears at the angle bisecting the axes $\left(45^{\circ}\right)$; the reappearance of an aftereffect after this point must be in the opposite direction, due to the orthogonal spatial axes. This prediction was confirmed for the vertical axis, but Gibson's theory cannot account for the reappearance of the positive aftereffect beyond $45^{\circ}$ which was found for the horizontal axis. Kohler's theory of satiation and repulsion can account for the development of a positive aftereffect up to $45^{\circ}$ angular

Table 2. Mean aftereffects and SDs (in degrees) together with adjustment times for Experiment 2

\begin{tabular}{lccccccccccc} 
& $0^{\circ}$ & $10^{\circ}$ & $20^{\circ}$ & $30^{\circ}$ & $40^{\circ}$ & $45^{\circ}$ & $50^{\circ}$ & $60^{\circ}$ & $70^{\circ}$ & $30^{\circ}$ & $90^{\circ}$ \\
\hline Mean & 0.55 & 2.11 & 4.32 & 5.98 & 6.79 & 3.18 & 5.67 & 7.76 & 6.29 & 4.98 & -0.99 \\
SD & 3.49 & 2.94 & 2.95 & 2.87 & 3.07 & 2.86 & 3.46 & 4.30 & 3.89 & 3.75 & 3.52 \\
Adjustment time & 7.8 & 6.9 & 6.1 & 7.1 & 6.1 & 3.7 & 6.4 & 6.8 & 7.4 & 7.0 & 7.2 \\
Significance & NS & NS & $*$ & $*$ & $*$ & ${ }^{*}$ & $*$ & $*$ & $*$ & $*$ & NS \\
\hline
\end{tabular}

* Significant at 0.05 level 


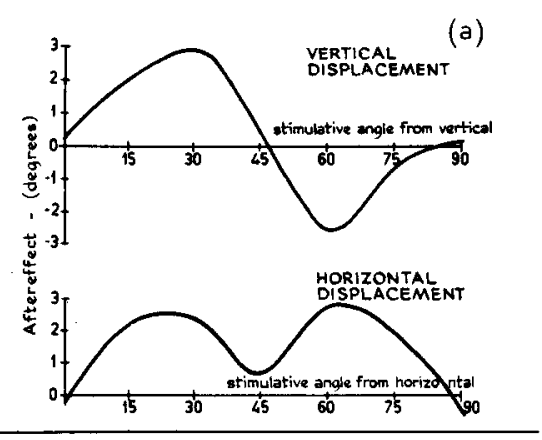

(b)

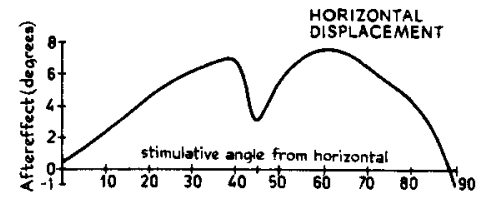

Fig. 3(a). The effect of angular displacement from the vertical and horizontal planes on the kinesthetic spatial aftereffect found in Experiment 1.

Fig. 3(b). The effect of angular displacement from the horizontal plane on the kinesthetic spatial aftereffect found in Experiment 2.

displacement from both norms. However, once the aftereffect has disappeared any further aftereffect in either direction as found in this experiment defies explanation by the satiation principle.

The interaxial difference found in the KSAE indicates that the kinesthetic system does not behave in the same manner as the visual system for which the traditional theories of aftereffects have been formulated. The explanation for the findings reported here probably lies in the structure of the joints concerned. Further investigation is needed to see if it is purely a local effect or whether such a difference is found throughout the kinesthetic system.

\section{References}

Collins, J. K. Freedom and restriction of the limbs in the kinesthetic spatial aftereffect. Aust. J. Psychol., 1967a, 19, 63-67

Collins, J. K. A kinesthetic spatial aftereffect with pronation of the forearm. Aust. J. Psychol., 1967b, 19, 117-120.

Collins, J. K., \& Singer, G. The interaction between sensory spatial aftereffects and persistence of response following behavioral compensation. J. exp. Psychol., (in press).

Day, R. H. \& Singer, G. Intermodal spatial aftereffects within and between kinesthesis and vision. J. exp. Psychol., 1964, 68, 337-343.

Gibson, J. J. Adaptation, aftereffect and contrast in the perception of curved lines. J. exp. Psychol., 1933, 16; 1-31.

Gibson, J. J., \& Radner, M. Adaptation, aftereffect and contrast in the perception of tilted lines. 1. Quantitative studies. J. exp. Psychol., 1937, 20, 453-467.

Köhler, W. Unsolved problems in the field of figural aftereffects. Psychol. Rev., 1965, 15, 63-83.

Kôhler, W., \& Wallach, H. Figural aftereffects: An investigation of visual processes. Proc. Amer. Phil. Soc., 1944, 88, 269-357.

Rodger, R. S. Intermediate statistics. Sydney: University Co-operative Bookshop, 1965.

Singer, G., \& Day, R. H. Temporal determinants of a kinesthetic spatial aftereffect. J. exp. Psychol., 1965, 69, 343-348.

(Accepted for publication November $6,1967$. ) 